\title{
Throughput Analysis on Dynamic Spectrum Allocation Technique to Mitigate Interference on LTE Heterogeneous Network
}

\author{
Nurzati Iwani Othman, Ahmad Fadzil Ismail, Mohammad Kamrul Hasan, \\ Khairayu Badron and Wahidah Hashim \\ Faculty of Engineering, International Islamic University Malaysia \\ College of Computer Science \& Info Tech, Universiti Tenaga Nasional Malaysia \\ nurzati.iwani90@yahoo.com,af_ismail@iium.edu.my,hasankamrul@ieee.org, \\ khairayu@iium.edu.my,wahidah@uniten.edu.my
}

\begin{abstract}
The use of mobile devices has gradually increased over time. It has become a necessity for people to own mobile devices in order to communicate with others all around the world. With increasing number of users, the LTE network service providers need to think of a way on how to enhance their service so that users can experience faster internet experience without any disruption from the network. In a heterogeneous network that consists of several base stations and scores of users, cross-tier interference is bound to occur. Cross-tier interference can cause loss of signal and drop calls. In this paper, a Dynamic Spectrum Allocation (DSA) technique was proposed and implemented in a LTE network configuration. At this juncture, the study only focuses on the segment involving communication downlink. Software development toolkit GNU Radio was used in the assembly of the network configurations. Throughput comparison was then made against a normal LTE network configuration. The throughputs of both configurations were computed and assessed. Configuration embedded with DSA managed to achieve higher throughput. The findings suggest that DSA is a technique capable of mitigating interference for LTE network.
\end{abstract}

Keywords: Dynamic Spectrum Allocation (DSA), Long Term Evolution (LTE), Orthogonal Frequency Division Multiplexing (OFDM), Heterogeneous Networks (HetNets)

\section{Introduction}

Heterogeneous networks (HetNets) consisting of macrocell and femtocell base stations as well as their users will likely to experience interference. Figure 1 shows a network scenario involving a macrocell base station (MBS), femtocell base station (FBS), macrocell users ( $u \mathrm{MBS})$ and femtocell users $(u \mathrm{FBS})$. In a heterogeneous network, there are two types of communication links, the uplink communication (UL) and downlink communication (DL). UL is the data transmission from the user device to base station, whereas DL is vice versa. When the base stations share the same carrier frequency, crosstier interference will take place.

Received (August 28, 2017), Review Result (November 18, 2017), Accepted (November 26, 2017) 


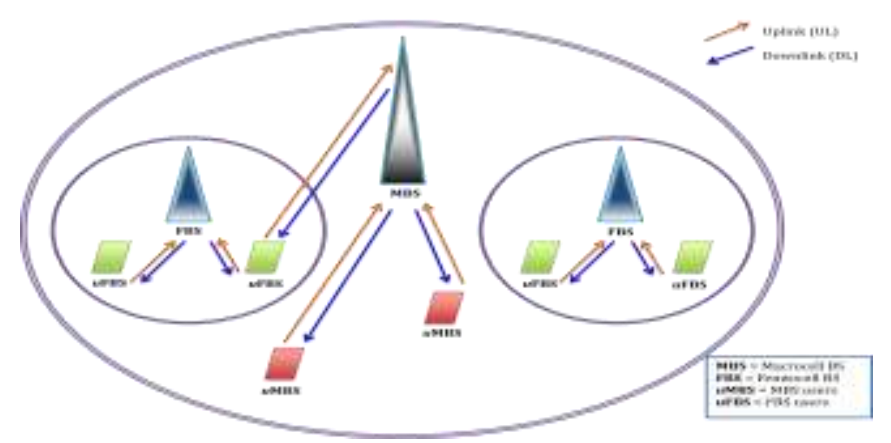

Figure 1. Uplink and Downlink Communication Scenario in HetNets

There are many techniques currently being researched on how to enhance the performance of LTE wireless networks. The effectiveness of each proposed technique can be based on several output parameters such as error rates, throughputs, data rates and more. For example, by assessing the acquired throughput by the receivers, it can then be established whether the technique had managed to reduce or mitigate interference within the network. Previous investigators [1] had conducted studies of previously proposed interference management techniques that involve single hop, multi-hop and multi-way network configurations. Several challenges were identified from the study such as out-ofcell interference and many more. Researchers [2] proposed a two-dimensional optimization of resource pattern based on variable channel conditions. Based on their findings, it appears that they have managed to reduce interference by introducing a technique that exploits the channel variations both in time and frequency domains. Researchers [3] had proposed a spectrum splitting-based cognitive interference management technique for LTE downlink two-tier networks. Resource-blocks in the MBS will be allocated and reserved for users with received signal to noise ration SINR higher than the set threshold. In their studies, the investigators also managed to prove that they were able to increase the average throughput of FBS cell-edges. Investigators [4] on the other hand had suggested what is considered as a low-complexity, distributed interference mitigation technique, yet with sensing capability of network load and propagation conditions.

Researchers had also investigated a system model of frequency domain load balancing based inter-cell interference coordination (ICIC) to minimize the total interference, while at the same time capable of satisfying the required quality of service constraints [5]. They proposed an intelligent antenna allocation operating at the base station with the capability to proficiently manage interferences. Another team of researchers had proposed Dynamic Frequency Reuse (DMFR) technique claimed capable of enhancing both the cell edge and adjacent sector transmission performance through adaptive spectrum allocation, interference management and CoMP techniques [6]. They have highlighteds that DMFR can mitigate interference better than Fractional Frequency Reuse (FFR) in terms of higher throughput and a more efficient spectrum utilization. Investigators also implied that interference can be mitigated by enhancing the convergence speed of communication links [7]. Their simulation results show that the proposed technique managed to achieve a significant improvement in system performance for heterogeneous deployment with noncooperating agents. There had also been a study that proposed a novel fractional frequency reuse-based dynamic resource allocation (DRA) algorithm at the secondary (cellular) network [8]. The researchers consider a cooperative spectrum sharing architecture in which the secondary user is assumed to be a cellular network. They then compared the system throughput and fairness of their system with the traditional resource allocation techniques. Preceding researchers did propose a generic spectrum allocation technique, which to certain extent can dynamically allocates the spectrum between MBS 
and FBS [9]. In their findings, they had identified that user will keep on getting high data rates even if user density increases.

The paper is organized by firstly introducing the several types of interference mitigation techniques for wireless network and previous studies on dynamic spectrum allocation. Section two introduces the proposed DSA algorithm and how it is being configured using the GNU Radio software, Section three highlights the mathematical expressions employed for this test, followed by parameters used in Section four. Section five discusses the results and discussion and lastly, conclusion is summarized in Section six.

\section{Proposed DSA Algorithm using GNU Radio Software}

\section{a) Proposed DSA Algorithm}

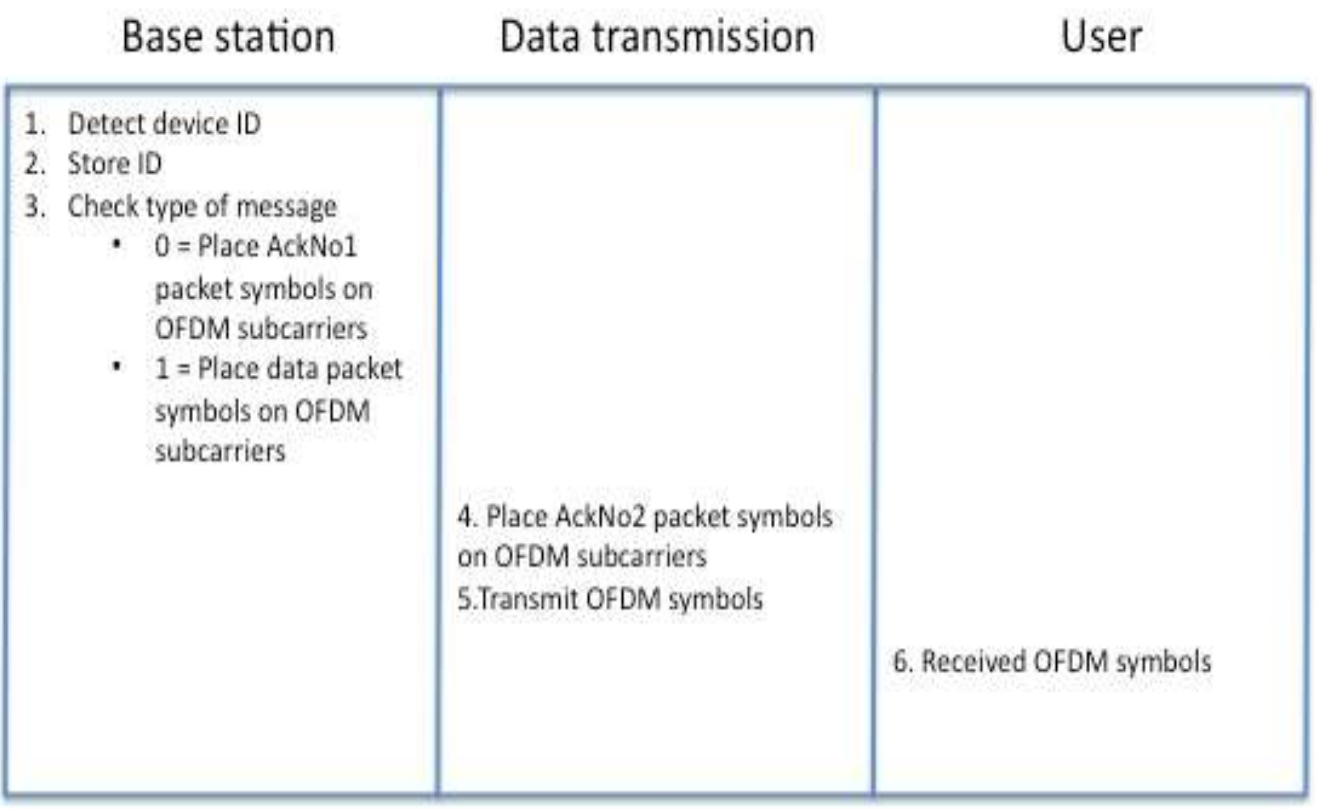

Figure 2. Flow Chart of the Proposed DSA Algorithm

Figure 2 shows sequence for the implementation of proposed DSA algorithm deployed in the study. The feasibility of implementing DSA algorithm was inspired by a very convincing previous analysis [10]. The coding and design of the flow graph using the GNU Radio software had been modified accordingly based on the requirements of this project. The flow sequence which is also identified as the scheduler had been programmed into the base station core block shown in in the flow graph labelled as Figure 3(a). The algorithm employed is known as the Nash Bargaining Solution. It starts by detecting the device ID and once detected, the device ID will be stored and the type of message will be checked. If the device ID is not detected, then the system will repeat the detection process. If the message type is 0 , then acknowledgement no. 1 packet symbols will be placed on OFDM subcarriers. If the message type is 1 , then the data packet symbols will be placed on OFDM subcarriers. Then, if the message type is 2 , the device ID will be removed. Once the packet has ended, acknowledgement no. 2 packet symbols will be placed on OFDM subcarriers and finally, the OFDM symbols will be transmitted. The system will continue to iterate until all the subcarriers are occupied. 


\section{b) LTE Configuration Flowgraph using GNU Radio Software}

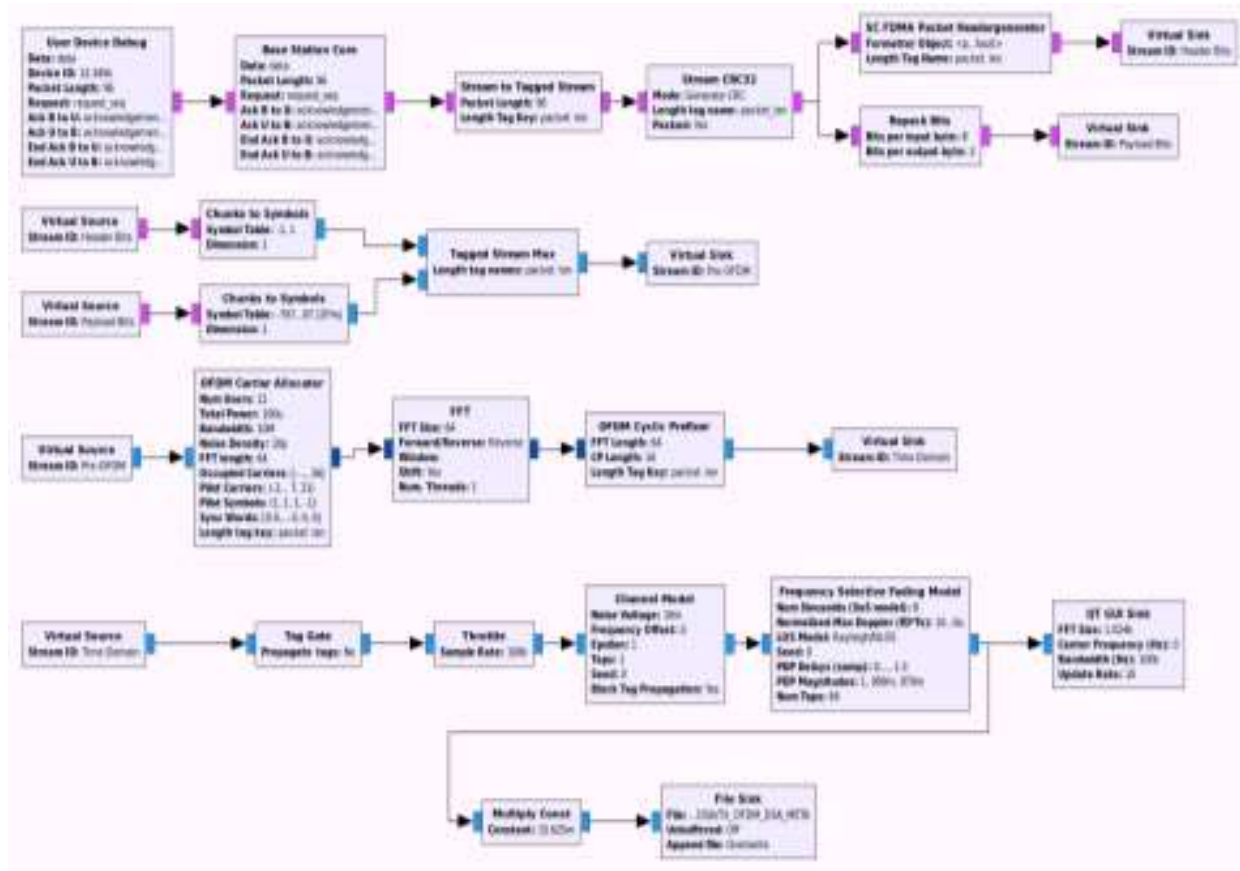

Figure 3(a). Flowgraph of LTE Configuration with DSA Implementation (Transmitter)

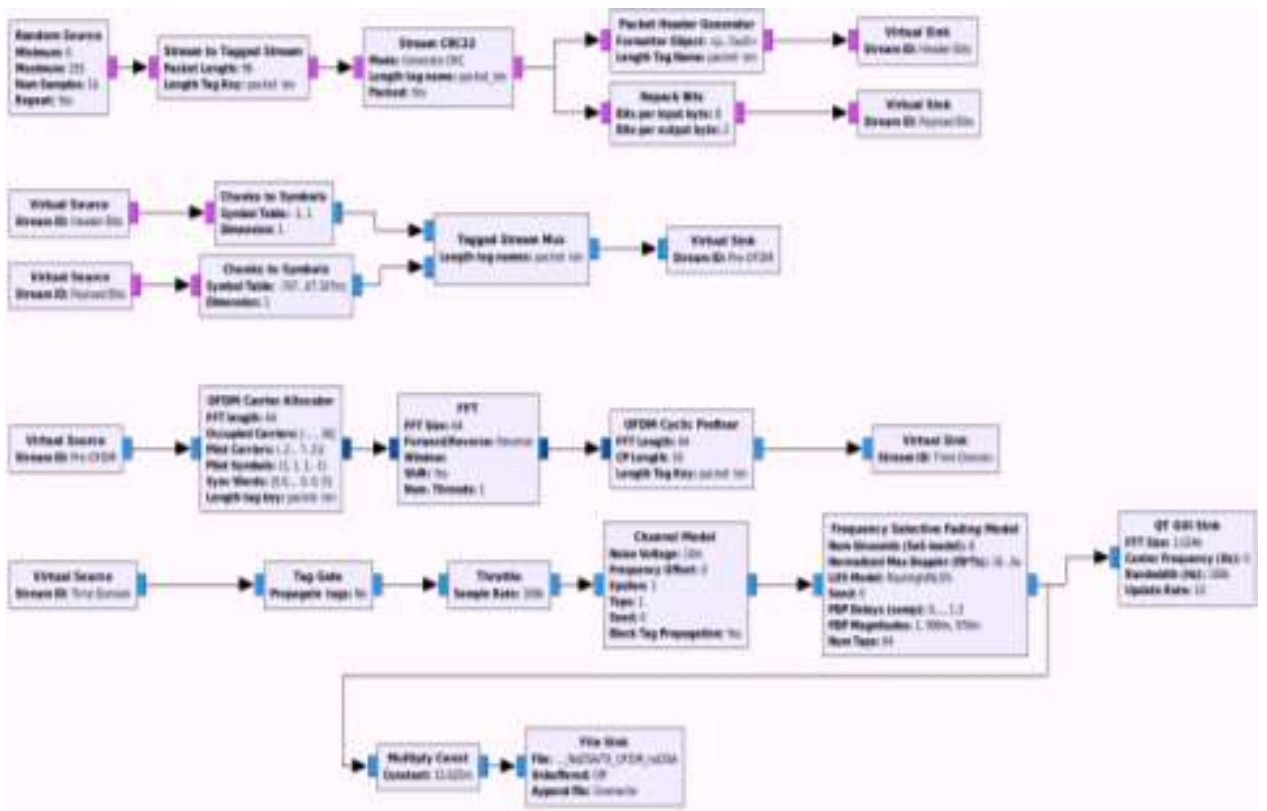

Figure 3(b). Flowgraph of Normal LTE Configuration with (Transmitter)

Figure 3(a) and (b) show the flow graphs of LTE configuration with and without DSA implementation. These flow graphs basically show the series of processing blocks data connection that establish the data flow. The difference between these two configurations is the source of data. The normal LTE configuration uses a random source block, where random binary data will be generated and no DSA scheme is programmed into the block. On the other hand, in the configuration with DSA, data is generated using the Base Station Core block, where the DSA algorithm has already been programmed. 


\section{Mathematical Expression}

In order to compute the throughput of a network, the lists of formula used were adapted from previously publish literature [11]. The path loss between macrocell users, $u \mathrm{MBS}$ and macrocell base station, MBS (with frequency of $2 \mathrm{GHz}$ ), denoted by $P L_{u M B S}$, can be calculated using Equation (1),

$$
P L_{u M B S}[d b]=15.3+37.6 \log (d[m])+S^{\text {out }}
$$

where $d$ is the distance between transmitter and receiver and $S^{\text {out }}$ is the outshadowing factor which is characterized by the Gaussian distribution with zero mean and deviation. The formula for path loss, denoted by $P L_{u F B S}$, of femtocell users, $u$ FBS and femtocell base station, FBS is shown in Equation 2,

$$
P L_{u F B S}[d B]=38.46+20 \log (d[m])+0.7 d_{2 D, \text { indoor }}+18.3 n^{((n+2)(n+1)-0.46)}
$$

where $n$ is the number of penetrated floors. For a single story house, the last term is equal to zero. The term $0.7 d_{2 D \text {,indoor }}$ is the distance when considering the penetration loss by the walls inside a house. Then, the channel gain can be computed using Equation 3,

$$
G=1{\stackrel{-P}{0^{1}}}^{0}
$$

For the case of $u \mathrm{MBS}, m$ on subcarrier $n$, both the impact of the adjacent MBS and overlaid FBS had to be considered. Thus, the signal to interference plus noise ratio, SINR is as shown in Equation 4,

$$
S \quad{ }_{m, n} I=\frac{G_{M, m, n} \cdot P_{M, n}}{\sigma_{n}^{2}+\sum_{n} G_{\substack{m, n \\ e}} \cdot P_{i}{ }_{i}+{ }_{i}+\sum_{g F} G_{m, F g i} \cdot P_{F,},}
$$

where $P_{X, n}$ is the transmit power of the serving BS $X$ on subcarrier $n$ ( $X$ can be either the macrocell $M$ or the neighboring macrocell neigM or the femtocell $F$ ), $G_{x, X, n}$ is the channel gain between user $x$ and the serving cell $X$ (where $x$ can be a $u$ MBS or a $u$ FBS and $X$ is serving BS) and lastly $\sigma_{n}^{2}$ is the power of the Additive White Gaussian Noise (AWGN). On the other hand, the SINR of a $u$ FBS when considering the interference caused by neighboring femtocells (neigF) and the macrocells that use the same frequency bands is arranged as in Equation 5,

$$
S \quad f_{, h}=\frac{G_{F, f, n} \cdot P_{F, n}}{\sigma_{n}^{2}+\sum_{n} G_{f, n}{ }_{, n}+\sum_{i} \sum_{M} G_{f i M, n} \cdot P_{F, n}}
$$

The capacity of user $x$ is then can be calculated using Equation 6,

$$
C_{x, n}=\Delta f \cdot \log _{2}\left(1+a \operatorname{SINR} R_{x, n}\right)
$$

where $\Delta f$ is the subcarrier spacing and $a$ is connected with the target bit error rate (BER), $a=-1.5 / \ln$ (BER). Finally, the throughput of a serving macrocell was calculated using Equation 7, 


$$
T_{M}=\sum_{M} \sum_{N} \beta_{m, n} \cdot C_{m, n}
$$

where $\beta$ is the subcarrier assignment.

\section{Parameters Used}

Table 1. Parameters Used in this Project

\begin{tabular}{|l|c|c|}
\hline \multicolumn{1}{|c|}{ Parameter } & $\begin{array}{c}\text { Normal LTE configuration } \\
\text { (LTE_normal) }\end{array}$ & $\begin{array}{c}\text { DSA implemented LTE } \\
\text { configuration (LTE_DSA) }\end{array}$ \\
\hline Source of data & Random source block & Base station core block \\
\hline FFT length & 64 bytes & 64 bytes \\
\hline CP length & 16 bytes & 16 bytes \\
\hline Bandwidth (Hz) & $10 \mathrm{M}$ & $10 \mathrm{M}$ \\
\hline $\begin{array}{l}\text { Multiplexing } \\
\text { method }\end{array}$ & OFDM & OFDM \\
\hline $\begin{array}{l}\text { Modulation } \\
\text { scheme }\end{array}$ & QPSK & QPSK \\
\hline Noise source & Gaussian with Amplitude $=1$ & Gaussian with Amplitude $=1$ \\
\hline
\end{tabular}

Table 1 lists the parameters used in this project. As can be observed, all of the parameters used in both configurations are the same except for the source of data. The bandwidth used for both the configurations is $10 \mathrm{MHz}$ and both configurations also used OFDM as the multiplexing method. These two parameters are the validations that the designs comply with LTE standard configurations. For both configurations, Gaussian noise had been introduced as the noise source, as portrayed in Figure 4 below. The amplitude in all cases was set as 1 .

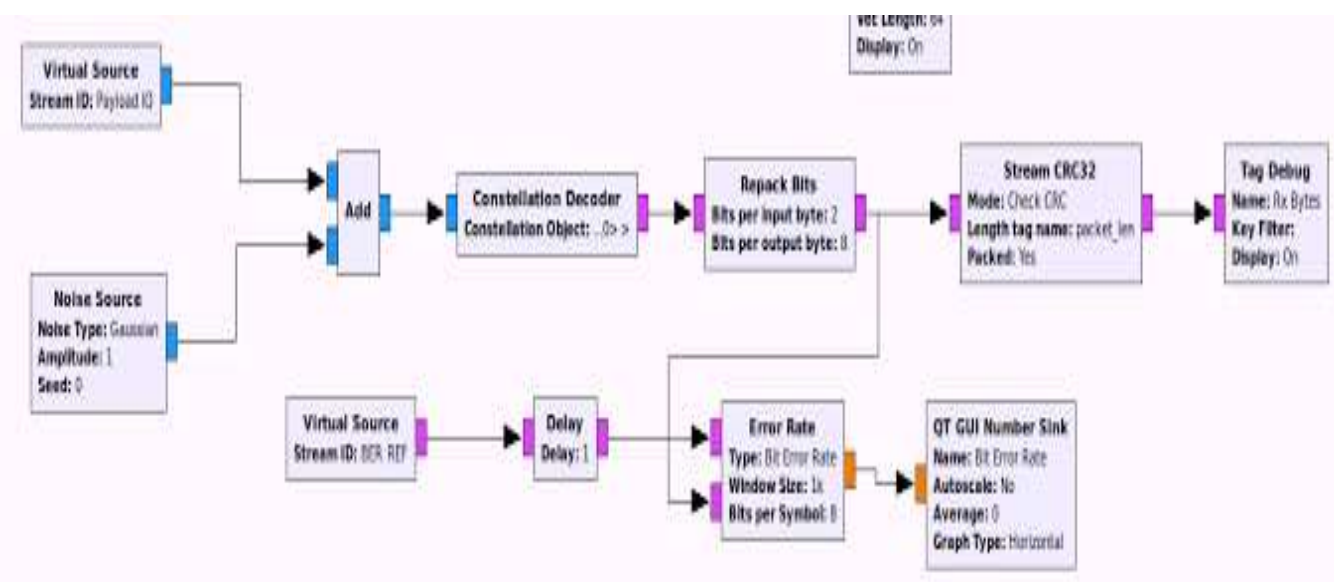

\section{Figure 4. Noise Source for both Normal LTE Configuration and DSA Implemented LTE Configuration}

Figure 6 shows the generated output from the constellation decoder at the receivers of both configurations. There are four dots, confirming that the modulation scheme used was QPSK. QPSK was used because QPSK can encode two bits per symbol, which is twice the rate of BPSK that in turn can minimize the BER. 


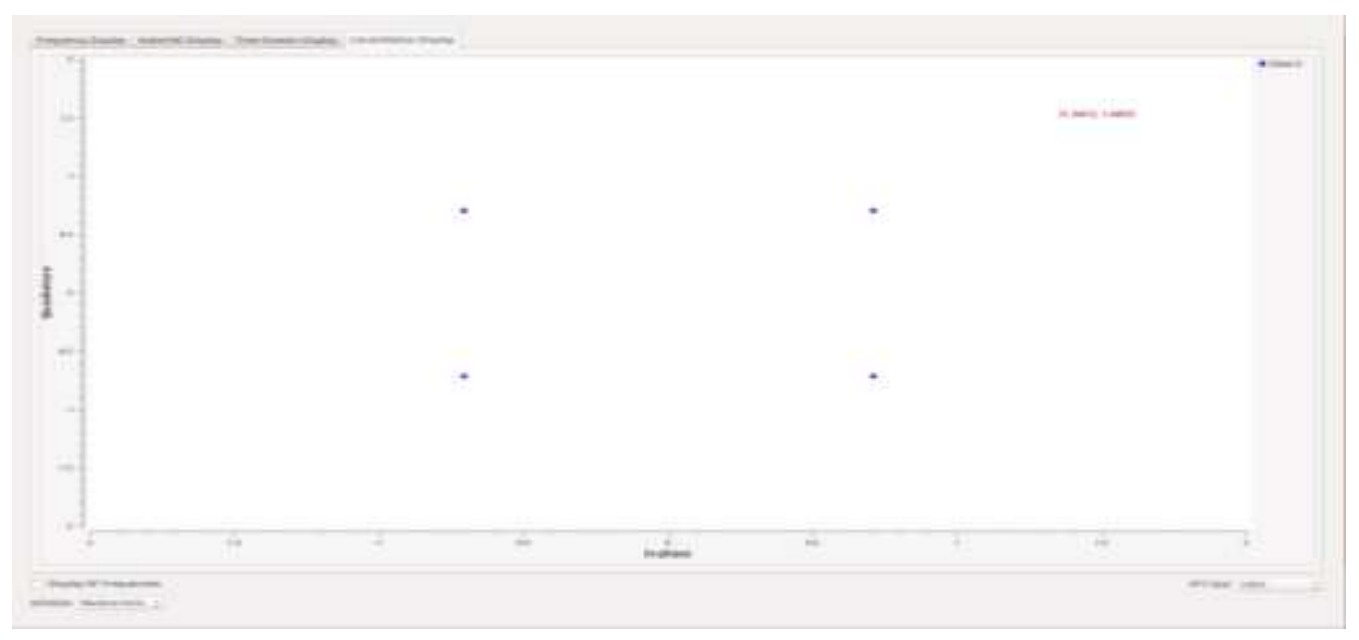

Figure 5. Constellation Display at the Receiver (QPSK modulation)

\section{Simulation Result and Discussion}

a) Comparison of output signals from normal LTE configuration and LTE configuration by implementing DSA technique.

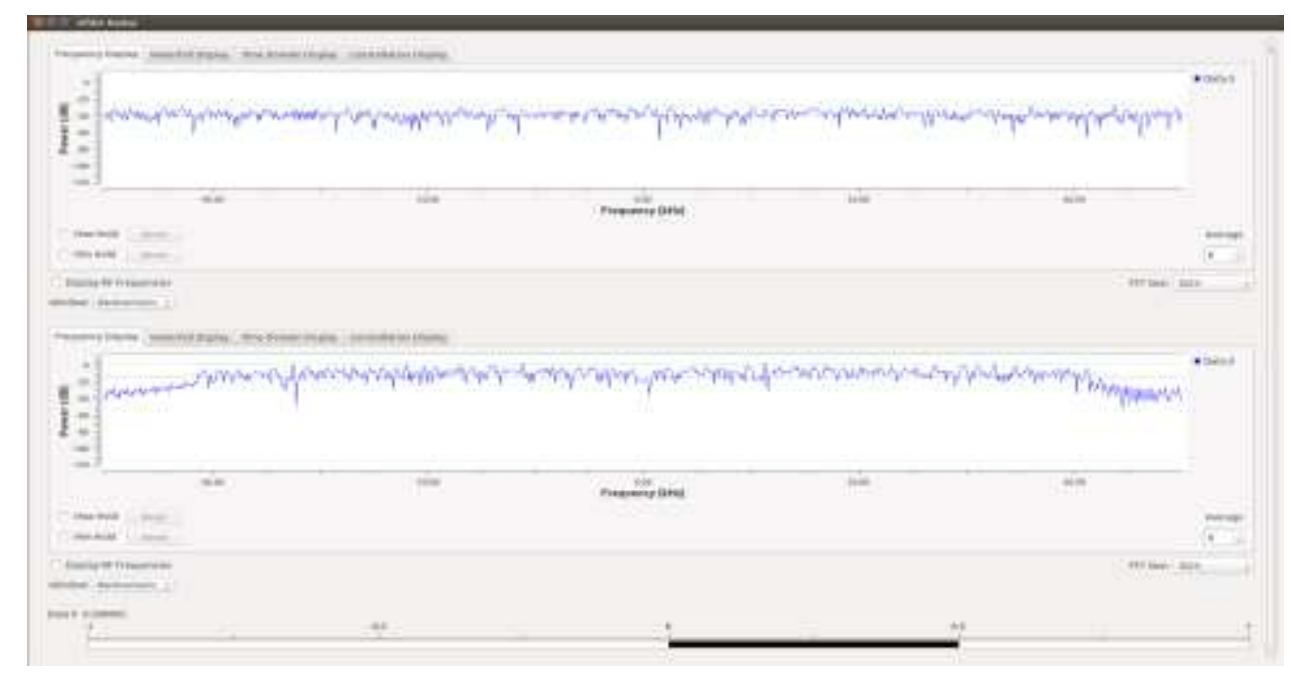

Figure 6(a). Output Signals Generated from the Normal LTE Configuration (for Gaussian noise $=$ Amplitude of 1 )

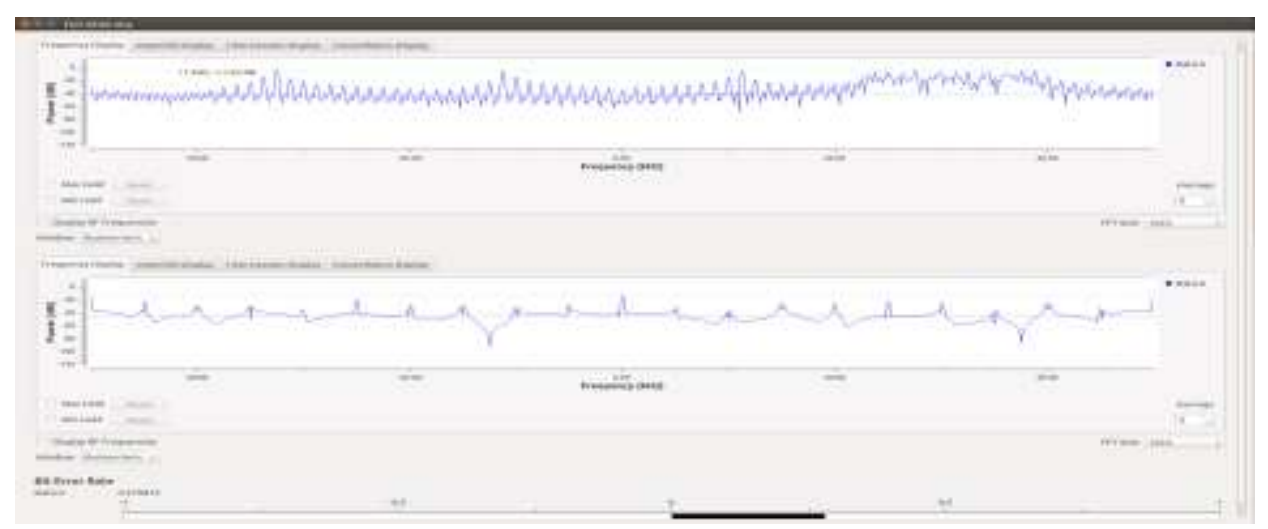

Figure 6(b). Output Signals Generated from the LTE Configuration with DSA Implementation (for Gaussian noise = Amplitude of 1 ) 
Figure 6(a) and (b) show the output signals generated from both configurations. It can be seen that the output signal for the normal LTE configuration exhibits signal which has more peaks as compared to LTE configuration with DSA implementation. This shows that the interference for the normal LTE configuration is higher than the one with DSA implementation. On top of that, the BER for the normal LTE configuration is a higher by $44 \%$ than the second one. This explains that there are more errors present in the normal LTE configuration caused by interferences.

c) Throughput Analysis

Table 2. Parameters Assumed and Data Collected from Simulation of the Flow Graphs

\begin{tabular}{|c|c|c|c|c|c|c|c|c|c|c|}
\hline $\begin{array}{l}\text { Noise source } \\
\text { amplitude }\end{array}$ & \multicolumn{2}{|c|}{1} & \multicolumn{2}{|c|}{2} & \multicolumn{2}{|c|}{3} & \multicolumn{2}{|c|}{4} & \multicolumn{2}{|c|}{5} \\
\hline Item & $\begin{array}{c}\text { N- } \\
\text { LTE }\end{array}$ & $\begin{array}{l}\text { DSA } \\
\text { LTE }\end{array}$ & $\begin{array}{c}\text { N- } \\
\text { LTE }\end{array}$ & $\begin{array}{l}\text { DSA } \\
\text { LTE }\end{array}$ & $\begin{array}{c}\text { N- } \\
\text { LTE }\end{array}$ & $\begin{array}{l}\text { DSA } \\
\text { LTE }\end{array}$ & $\begin{array}{c}\text { N- } \\
\text { LTE }\end{array}$ & $\begin{array}{l}\text { DSA } \\
\text { LTE }\end{array}$ & $\begin{array}{c}\text { N- } \\
\text { LTE }\end{array}$ & $\begin{array}{l}\text { DSA } \\
\text { LTE }\end{array}$ \\
\hline $\begin{array}{l}\text { Distance } \\
\text { between TX } \\
\text { and RX } d[\mathrm{~m}]\end{array}$ & 20 & 20 & 20 & 20 & 20 & 20 & 20 & 20 & 20 & 20 \\
\hline $\begin{array}{l}\text { Outshadowin } \\
\mathrm{g} \text { factor, } S^{\text {out }} \\
{[d B]}\end{array}$ & 10 & 10 & 10 & 10 & 10 & 10 & 10 & 10 & 10 & 10 \\
\hline $\begin{array}{l}\text { Calculated } \\
\text { path loss for } \\
\text { MBS, } \\
\text { PLuMBS[dB] }\end{array}$ & 74.22 & 74.22 & 74.22 & 74.22 & 74.22 & 74.22 & 74.22 & 74.22 & 74.22 & 74.22 \\
\hline $0.7 d_{2 D, \text { indoor }}$ & $\begin{array}{l}0.7(5) \\
=3.5\end{array}$ & $\begin{array}{l}0.7(5) \\
=3.5\end{array}$ & $\begin{array}{l}0.7(5) \\
=3.5\end{array}$ & $\begin{array}{l}0.7(5) \\
=3.5\end{array}$ & $\begin{array}{l}0.7(5) \\
=3.5\end{array}$ & $\begin{array}{l}0.7(5) \\
=3.5\end{array}$ & $\begin{array}{l}0.7(5) \\
=3.5\end{array}$ & $\begin{array}{l}0.7(5) \\
=3.5\end{array}$ & $\begin{array}{l}0.7(5) \\
=3.5\end{array}$ & $\begin{array}{l}0.7(5) \\
=3.5\end{array}$ \\
\hline $\begin{array}{l}\text { Penetrated } \\
\text { floors no., } n\end{array}$ & 0 & 0 & 0 & 0 & 0 & 0 & 0 & 0 & 0 & 0 \\
\hline $\begin{array}{l}\text { Calculated } \\
\text { path loss for } \\
\text { FBS, } \\
P L_{u F B S}[d B]\end{array}$ & 67.98 & 67.98 & 67.98 & 67.98 & 67.98 & 67.98 & 67.98 & 67.98 & 67.98 & 67.98 \\
\hline $\begin{array}{l}\text { Channel } \\
\text { gain } \\
\text { macrocell, } \\
G_{m}\end{array}$ & $37.8 n$ & $37.8 n$ & $37.8 n$ & $37.8 n$ & $37.8 n$ & $37.8 n$ & $37.8 n$ & $37.8 n$ & $37.8 n$ & $37.8 \mathrm{n}$ \\
\hline $\begin{array}{l}\text { Channel } \\
\text { gain } \\
\text { femtocell, } G_{f}\end{array}$ & $\begin{array}{c}159.2 \\
\mathrm{n}\end{array}$ & $\begin{array}{c}159.2 \\
\mathrm{n}\end{array}$ & $\begin{array}{c}159.2 \\
\mathrm{n}\end{array}$ & $\begin{array}{c}159.2 \\
\mathrm{n}\end{array}$ & $\begin{array}{c}159.2 \\
\mathrm{n}\end{array}$ & $\begin{array}{c}159.2 \\
\mathrm{n}\end{array}$ & $\begin{array}{c}159.2 \\
\mathrm{n}\end{array}$ & $\begin{array}{c}159.2 \\
\mathrm{n}\end{array}$ & $\begin{array}{c}159.2 \\
\mathrm{n}\end{array}$ & $\begin{array}{c}159.2 \\
\mathrm{n}\end{array}$ \\
\hline $\begin{array}{l}\text { Macrocell } \\
\text { transmit } \\
\text { power, } P_{m} \\
{[\mathrm{~W}]}\end{array}$ & 20 & 20 & 20 & 20 & 20 & 20 & 20 & 20 & 20 & 20 \\
\hline $\begin{array}{l}\text { Femtocell } \\
\text { transmit } \\
\text { power, } P_{f} \\
{[\mathrm{~mW}]}\end{array}$ & 20 & 20 & 20 & 20 & 20 & 20 & 20 & 20 & 20 & 20 \\
\hline $\begin{array}{l}\text { Power of } \\
\text { AWGN, } \sigma_{n}^{2}\end{array}$ & $10 p$ & $10 p$ & $10 p$ & 10p & 10p & 10p & $10 p$ & $10 p$ & $10 p$ & $10 p$ \\
\hline$S I N R_{m, n}[d B]$ & 1 & 1 & 1 & 1 & 1 & 1 & 1 & 1 & 1 & 1 \\
\hline $\operatorname{SINR}_{f, n}[d B]$ & 0.02 & 0.02 & 0.02 & 0.02 & 0.02 & 0.02 & 0.02 & 0.02 & 0.02 & 0.02 \\
\hline BER & 0.5 & 0.28 & 0.625 & 0.37 & 0.625 & 0.412 & 0.625 & 0.434 & 0.75 & 0.453 \\
\hline $\begin{array}{l}a=- \\
1.5 \ln (\text { BER })\end{array}$ & 1.04 & 1.9 & 0.71 & 1.49 & 0.71 & 1.33 & 0.71 & 1.25 & 0.43 & 1.19 \\
\hline $\begin{array}{l}\text { Subcarrier } \\
\text { spacing, } \Delta f \\
{[\mathrm{~Hz}]}\end{array}$ & $15 \mathrm{k}$ & $15 \mathrm{k}$ & $15 k$ & $15 k$ & $15 k$ & $15 k$ & $15 k$ & $15 k$ & $15 k$ & $15 k$ \\
\hline $\begin{array}{l}\text { Capacity } \\
\text { macrocell, }\end{array}$ & $15.4 \mathrm{k}$ & $23 k$ & 11.6k & $19.7 \mathrm{k}$ & 11.6k & $18.3 \mathrm{k}$ & 11.6k & $17.5 \mathrm{k}$ & $7.7 \mathrm{k}$ & $17.0 \mathrm{k}$ \\
\hline
\end{tabular}




\begin{tabular}{|l|c|c|c|c|c|c|c|c|c|c|}
\hline$C_{m, n}$ & & & & & & & & & & \\
\hline $\begin{array}{l}\text { Capacity } \\
\text { femtocell, } \\
C_{f, n}\end{array}$ & 445 & 807 & 305 & 160 & 305 & 568 & 305 & 534 & 185 & 509 \\
\hline $\begin{array}{l}\text { Subcarrier } \\
\text { assignment, } \\
\beta\end{array}$ & 1 & 1 & 1 & 1 & 1 & 1 & 1 & 1 & 1 & 1 \\
\hline $\begin{array}{l}\text { Throughput, } \\
T \text { [bit/s] }\end{array}$ & $15.9 \mathrm{k}$ & $23.8 \mathrm{k}$ & $11.9 \mathrm{k}$ & $19.9 \mathrm{k}$ & $11.9 \mathrm{k}$ & $18.9 \mathrm{k}$ & $11.9 \mathrm{k}$ & $18.0 \mathrm{k}$ & $7.9 \mathrm{k}$ & $17.5 \mathrm{k}$ \\
\hline $\begin{array}{l}\text { Throughput } \\
\text { s difference }\end{array}$ & \multicolumn{2}{|c|}{$50.2 \%$} & \multicolumn{7}{|c|}{$67.2 \%$} & \multicolumn{7}{|c|}{$58.8 \%$} & $51.3 \%$ & $121.5 \%$ \\
\hline RMSE & \multicolumn{7}{|c|}{0.19605} \\
\hline
\end{tabular}

Table 2 lists the parameters involved and outputs generated from simulation of the flow graphs. The values for transmit power, distance and number of penetrated floors are assumed based on the limitations of a typical campus-based laboratory. It was assumed that the configuration is based on a single story building. From the generated outputs, it is evident that the throughputs of LTE configuration incorporating DSA is significantly higher than that of the normal LTE configuration. When the noise amplitude was set to 1, the throughput of DSA implemented LTE configuration is higher by $50.2 \%$ than the normal LTE configuration. Subsequently, when the noise amplitude was increased to 2, the percentage difference increases and becomes 67.2\%. However, the percentage difference decreases when noise amplitude is set to 3 and 4, but increases tremendously when the noise amplitude is set to 5. Further investigation will be carried out in future study to inspect the influence of noise amplitude. The calculated average root mean square error (RMSE) for all five instances is 0.19605 , which can be considered as quite low. The generated higher throughput at various interference instances proved that DSA implementation can mitigate interference in the LTE configuration

\section{Conclusion}

The LTE configuration in a heterogeneous network setup with DSA implementation had been demonstrated to have higher throughput when compared against one without. The simulations results corroborated the hypothesis that that interference in a heterogeneous network can be commendably mitigated. Spectral efficiency can be improved when interferences are minimized and hence maximizing system throughput, it is intended in the very near future pursuit of empirical analyses involving implementation using USRP hardware. The findings can substantiate system compatible at hardware level, thus validate that it can be implemented in real life situations.

\section{Acknowledgments}

The authors acknowledge the Research Management Centre (RMC) of the International Islamic University Malaysia (IIUM) and Malaysian Ministry of Education (MOHE) for the financial support during the research. The research output is part of the deliverables for the research funded under IIUM's Research University Initiatives. The Fundamental Research Grant Scheme (FRGS) Research Project by Malaysian Ministry of Education sponsors this research in creation of novel theories and concepts.

\section{References}

[1] N. Lee and R. W. Heath Jr., "Advanced Interference Management Technique: Potentials and Limitations", IEEE Wireless Communications, (2016) June.

[2] P. Liu, "Two-Dimensional Resource Pattern Optimization for Interference Avoidance in Heterogeneous Networks", IEEE Transactions on Vehicular Technology, vol. 64, no. 8, (2015) August.

[3] D. Siswanto, "Spectrum Splitting-Based Cognitive Interference Management in Two-Tier LTE Networks", Wireless Communications Systems (ISWCS), 2014 11th International Symposium. 
[4] A. Chiumento, "Scalable LTE interference mitigation solution for HetNet deployment", IEEE WCNC 2014 - Workshop on Interference and Design Issues for Future Heterogeneous Networks.

[5] Y.-H. Lee, "Joint Component Carrier and Antenna Allocation for Heterogeneous Network in LTE-A System", 2014 IEEE 25th International Symposium on Personal, Indoor and Mobile Radio Communications.

[6] H.-C. Jang and W.-D. Wend, "Interference Management using Frequency Reuse and CoMP for LTEAdvanced Networks", Ubiquitous and Future Networks (ICUFN), 2015 Seventh International Conference.

[7] E. Bikov, "Smart Resource Allocation with Concurrent Learning Scheme for Heterogeneous LTE Smallcell Networks", IEEE Global Communications Conference (GLOBECOM), (2015).

[8] A. Kumar, "Dynamic Resource Allocation for Cooperative Spectrum Sharing in LTE Networks", IEEE Transactions on Vehicular Technology, vol. 64, no. 11, (2015) November.

[9] R. Vanlin Sathya and B. Reddy Tamma, "Dynamic Spectrum Allocation in Femto based LTE Network", Communication Systems and Networks (COMSNETS), 2013 Fifth International Conference.

[10] H. Cheng, "Implementation of Dynamic Resource Allocation for LTE System using GNU Radio", A Thesis submitted to the Graduate Faculty of George Mason University in Partial Fulfillment of the Requirements for the Degree of Master of Science Electrical and Computer Engineering, (2014).

[11] C. Bouras, "Fractional Frequency Reuse in Integrated Femtocell/Macrocell Environments", International Conference on Wired/Wireless Internet Communication, (2013). 